\title{
Ultrasound in diagnose \& treatment follow-up of abdominal pain due to intestinal tuberculosis
}

\author{
MG Ametembun \\ From 10th WINFOCUS World Congress on Ultrasound in Emergency and Critical Care \\ Kuala Lumpur, Malaysia. 16-19 November 2014
}

\section{Background}

Intestinal tuberculosis frequently causes abdominal pain.

\section{Objective}

To describe ultrasound in management of intestinal tuberculosis.

\section{Patients and methods}

This retrospective study was conducted at St Elisabeth Hospital, Flores, during February 2012 - August 2013 using ALOKA SD1100. Data were abstracted from medical records of all completed treated of intestinal tuberculosis cases.

\section{Result}

N 546(14-85y, x36,5y), 312(57\%) female, 234(43\%) male.

\section{Preceding treatment}

All with recurrent colic abdomen pain (some very severe), diarrhea/obstipation, distention, "doughy \& dam-board phenomena", constitutional symptoms, cough and X-ray suggestive lung tuberculosis. Intestinal ultrasound on the tympanic area were normal, but on dullness pain area were: a/hypo-peristaltic, irregular thickening heterogenic hypo-echoic, irregular margin of the wall, loss differentiation of the wall layers, with several oval/round nodular structures (patchy hyper-echoic non-shadowing with an irregular rim of lower echo-density, those suggestive granuloma process) within the wall and narrowing of the lumen.

\section{During 9-12 months of anti tuberculosis treatment}

All the symptoms \& signs, dullness area, wall thickening, lumen narrowing were disappeared gradually with better peristaltic at the affected area.

\section{After the treatment}

no abdominal pain/tenderness/doughy abdomen/dullness area/ constitutional sign \&symptoms anymore. Only 292 (53\%) then carried ultrasound at the end of treatment (economic reason) showed intestine wall thickening were decreased and normal peristaltic were seemed on the affected area, but the wall margin were still irregular.

\section{Conclusion}

Ultrasound was very useful for more thorough diagnosis \& follow-up the treatment of intestinal tuberculosis.

\section{Published: 9 March 2015}

\section{References}

1. AWARD FOR THE BEST PRESENTATION, WINFOCUS ENCOUREGEMENT AWARD: Recurrent Abdominal Pain Among The Disseminated Tuberculosis Cases In Saumlaki Community Health Centre, Tanimbar, The Remote Boundary Islands In West Of South-East Mollucas Indonesia. The 5th World Congress Ultrasound on Emergency and Intensive Medicine Care WINFOCUS (World Interactive Network Focused on Critical Ultrasound), Sydney; 2009.

2. Ultrasound Findings Of Abdominal Pain in Intestinal and Peritonitis Tuberculosis. The 3rd World Congress Ultrasound On Emergency And Intensive Medicine Care In Paris 2007.

doi:10.1186/2036-7902-7-S1-A5

Cite this article as: Ametembun: Ultrasound in diagnose \& treatment

follow-up of abdominal pain due to intestinal tuberculosis. Critical

Ultrasound Journal 2015 7(Suppl 1):A5. 